\title{
A General Theoretical Framework for Analyzing Capital Accumulation in Agriculture
}

\author{
MoAzam Mahmood*
}

\section{INTRODUCTION}

This paper presents a fremework for micro analysis of the conditions of agrarian accumulation at the farm level. Individual or group level accumulation is seen to result from the production environment given to the producers. The producers' micro environment is provided by the village, the region, the agrarian sector and the economy.

\section{LIMITATIONS OF THE TWO TYPES OF FRAMEWORK IN ANALYZING AGRARIAN ACCUMULATION}

The producer's micro environment, clearly results from wider macro influences like state policy, as well as micro influences from within the agrarian sector. Therefore, it is curious that two of the more influential theoretical frameworks that attempt to encapsulate this production environment take such opposite positions. One such framework is posited by a number of neoclassical studies that emphasize state policy and competitive behaviour and neglect other structural characteristics of the agricultural sector like access to factors of production. In contrast, the framework posited by induced innovation studies emphasizes the structural characteristics of the agricultural sector and neglects state policy. Therefore, for one school, the determinants of agrarian accumulation lie outside the agrarian sector. In this sense they influence the agrarian sector 'exogenously'. For the induced innovation school the determinants of agrarian accumulation mostly lie inside the agrarian sector. In this sense their influence on the agrarian sector is endogenous. Both frameworks are important in their emphasis but limited by their mutual neglect of each other's positions. These limitations are briefly examined in this section and they are shown to be overcome by combining the two frameworks in the next section.

*The author is Research Economist at the Pakistan Institute of Development Economics, Islamabad. 


\section{An Exogenous Framework}

If gross investment in one period consists of fixed and variable capital, a producer's gross investment in period 1 can vary from gross investment in period 2 because of:

(a) Factor substitution; like a change in the capital-labour ratio;

(b) Input intensification; like using another tractor, or more fertilizer; and

(c) Technical change; like replacing traditional seeds with HYVs.

Factor substitution is a change in the combination of inputs, but resulting in the same level of output, (Ellis 1988). That is, the output-input ratio remains constant, but the input combinations are varied, like capital and labour. With input intensification the output-input ratio also remains constant, but more use of one input leads to a proportional increase in output, like an increase in cropped area. This is a simple increase in the scale of production.

Technical change is an increase in output per unit of inputs. Since technical change mostly requires a change in inputs, so it is better defined as a decrease in inputs per unit of output. Bias in technical change is described with respect to the shares of capital and labour. Technical change is Hicks neutral if the shares of capital and labour remain constant. It is labour saving if the share of capital increases relative to the share of labour. And it is capital saving if the share of capital decreases relative to the share of labour (Ellis 1988).

Ellis shows that much of neoclassical production theory typically places the determinants of investment outside the agrarian sector, with the state and competition between producers (Ellis 1988). This is partly true in Pakistan, where the state largely determines agricultural input and output prices and has introduced technical change. So prices and technical change are given exogenously to the agrarian sector, irrespective of how the agrarian sector responds to them. Competition between producers is exogenously given to the agrarian sector in that producers do not choose voluntarily to compete, but are compulsorily involved in market relationships. So prices and technical change elicit producers' response, because producers are competitive. And this process is exogenously given to the agrarian sector.

According to neoclassical theory, relative changes in input prices cause factor substitution. Relative increases in the productivity of inputs are introduced to producers causing input intensities and/or technical change. Relative increases in output prices with respect to input prices again can be described as technical change. But the case of Hicks neutral input intensification which keeps the output-input ratio constant is difficult to categorise amongst these neoclassically possible outcomes of policy-induced investment increases. Relative input price changes will keep the output-input ratio constant but will not be Hicks neutral. Relative increases in input productivities can have Hicks neutral outcomes but the output-input ratio changes. Relative increases in output prices with respect to inputs can have Hicks neutral outcomes but the output-input price ratio changes again.

Therefore Hicks neutral change in the scale of production that keeps the output input ratio constant on a farm, is not a possible outcome of state policy changes in either input prices, output prices, or input productivities. Input price changes will change the Hicks neutrality. Output price changes and input productivity changes will alter the output-input price ratio. This seeming impossibility of a change in the scale of production without factor substitution or technical change is due to the neoclassical assumption of producers' equilibrium at optimal levels of output.

Given a set of technical coefficients and a set of output and input prices, all determined exogenously, the producer will equate marginal value products (MVP) of inputs to their prices to choose an optimal level of output. Diagram 1 shows that the MVP of an input equated to its market price P1 gives an input use of I1.

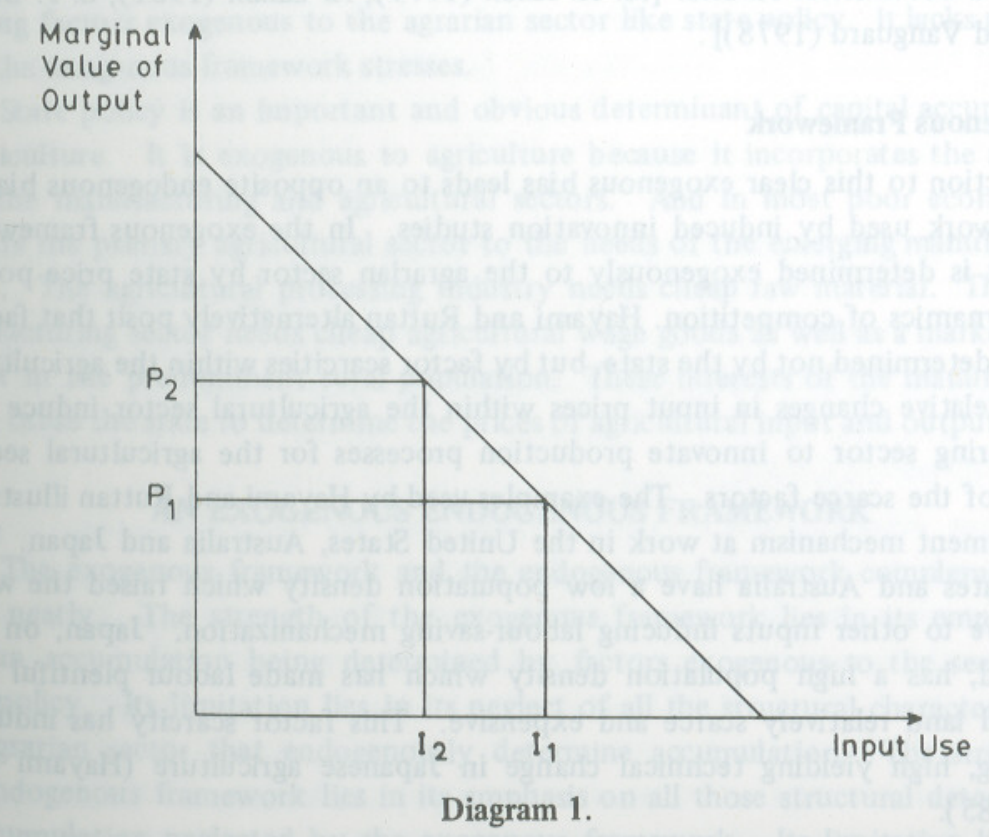

A level of use of I1, for all inputs gives the optimal scale of production. If all the technical coefficients and factor prices are given exogenously and there are no other constraints on the producer this will always be the case. But if the producer faces a supply shortage of all inputs at 12 , then a sub-optimal equilibrium output 
level will result. The factor bias and output-input ratio will be that of optimal equilibrium at I1, but the input use for all inputs will be lower. Therefore the removal of such supply rigidities allows a Hicks neutral increase in the scale of production which also keeps the output-input ratio constant. Prime examples of such supply rigidities are producers' financial constraints, rationing of scarce inputs at market prices and dominant landlords' pre-emption of such inputs. Therefore, theory that emphasizes. exogenous factors like state policy as the only determinant of investment increases cannot explain such important increases in the scale of investment and production. This neglect of a whole world of structural determinants of accumulation with the agrarian sector is a serious limitation.

A theoretical framework of accumulation that neglects the structural characteristics endogenous to the agrarian sector also results in the assumption of homogeneity of that sector in its conditions of accumulation. This can lead to the extrapolation of tendencies like polarization of operated area based on conditions in one region of the agrarian sector, to another region with different conditions and even to the entire sector. This assumption of sectoral homogeneity is a limitation of some Marxist and neoclassical studies. [M. H. Khan (1979); A. Salam (1981); S. J. Burki (1976); and Vanguard (1978)] .

\section{An Endogenous Framework}

Reaction to this clear exogenous bias leads to an opposite endogenous bias in the framework used by induced innovation studies. In the exogenous framework investment is determined exogenously to the agrarian sector by state price policy and the dynamics of competition. Hayami and Ruttan alternatively posit that factor prices are determined not by the state, but by factor scarcities within the agricultural sector. Relative changes in input prices within the agricultural sector induce the manufacturing sector to innovate production processes for the agricultural sector using less of the scarce factors. The examples used by Hayami and Ruttan illustrate the inducement mechanism at work in the United States, Australia and Japan. The United States and Australia have a low population density which raised the wage rate relative to other inputs inducing labour-saving mechanization. Japan, on the other hand, has a high population density which has made labour plentiful but agricultural land relatively scarce and expensive. This factor scarcity has induced land saving, high yielding technical change in Japanese agriculture (Hayami and Ruttan 1985)

Hayami and Ruttan's induced innovation mechanism provides much needed emphasis on the endogenous determinants of agrarian accumulation. In fact, the mechanism is much more broad based than they are given credit for. De Janvry, Grabowski and Ellis have all pointed out that a concentrated structure of land- ownership gives rise to a divergence in factor scarcities between large and small farmers. Large farmers need to self cultivate their estates with a minimal amount of labour to supervise and so require labour-saving large-scale mechanization. Small farmers, on the other hand, need land saving, yield-increasing technology and smallscale mechanization. Small Farmers also fear the labour-saving mechanization of large farmers which displaces them as tenants and can decrease the real wage of their hired out surplus labour. In such a bi-polar agrarian sector the factor scarcities of the large farmers will induce labour-saving mechanization which is not warranted by the factor scarcities of the small farmers (Janvry 1973).

Hayami argues back that such a socially inefficient and inequitable outcome does not vitiate the mechanism of the induced innovation model. This outcome in fact is a clear implication of the model (Hayami 1981). Therefore the model allows a large number of factors endogenous to the agrarian sector to critically determine the level and pattern of capital accumulation. Hayami and Kikichi even allow for regional heterogeneity and the encapsulation of village production environments as seen below (Hayami and Kikichi 1981).

However, the induced innovation model has the obvious limitation of entirely ignoring factors exogenous to the agrarian sector like state policy. It lacks precisely what the exogenous framework stresses.

State policy is an important and obvious determinant of capital accumulation in agriculture. It is exogenous to agriculture because it incorporates the needs of both the manufacturing and agricultural sectors. And in most poor economies it subjects the primary agricultural sector to the needs of the emerging manufacturing sector. The agricultural processing industry needs cheap raw material. The entire manufacturing sector needs cheap agricultural wage goods as well as a market for its output in the predominant rural population. These interests of the manufacturing sector cause the state to determine the prices of agricultural input and outputs.

\section{AN EXOGENOUS ENDOGENOUS FRAMEWORK}

The exogenous framework and the endogenous framework complement each other neatly. The strength of the exogenous framework lies in its emphasis on agrarian accumulation being determined by factors exogenous to the sector, like state policy. Its limitation lies in its neglect of all the structural characteristics of the agrarian sector that endogenously determine accumulation. The strength of the endogenous framework lies in its emphasis on all those structural determinants of accumulation neglected by the exogenous framework. Its limitation lies in its neglect of exogenous factors like state policy. Therefore, the two frameworks can simply be combined together to complement each other's strengths and cover each other's limitations. This gives an exogenous endogenous framework that provides a 
more comprehensive set of determinants of accumulation.

\section{The Notion of Capital}

A preliminary notion that needs to be clarified is that of capital. Capital is heterogenous by its very nature. As Pasinetti points out the difficulty is not that it is impossible to measure, but that it is measurable in too many ways. Therefore, the purpose of the measurement of capital is important (Pasinetti 1981).

The objective of this study is to examine accumulation of agricultural capital by producers, because it increases output. The notion of capital that suits this objective is the capacity to produce output. The process of accumulation of capital is then the expansion of the scale of output capacity (Marx 1973). Net investment expands capital stock. Gross investment embodies technical progress. Both contribute to the expansion of the capacity to produce output so this expansion can be embodied in factor substitution, input intensification and technical change as seen in the last section. A producer's capacity expansion can be observed through a set of conditions:

(i) Acquisition of productive assets;

(ii) Variable input intensification, factor substitution and technical change; and

(iii) Generation of farm profit.

Conditions (i) and (ii) show simple capacity expansion. Condition (iii) has to accompany (i) and/or (ii) in order to expand capacity. Capacity can be expanded without profit, through credit. But the credit still has to be repaid, or the increased capacity is repossessed. Therefore, profit must complement capacity expansion.

\section{Two Definitions of Capital}

These manifestations of capacity expansion are expected to vary between definable groups of people and definable regions. Some groups of people expand their means of production, while other lose them. Some regions expand their means of production faster than others. This heterogeneity between people and between regions requires a social definition of capital to complement the preliminary physical notion of capital used so far.

The normal usage of "capital" is as a physical construct. When capital is defined in this way, its growth is expressed as the expansion of production capacity. This directs the focus of the study towards an examination of the technical relationships between material inputs and outputs. This is a vital first step. But the separation of some people from the means of production serves as a reminder that labour power is a factor of production along with other material factors. People own the material factors of production, use them along with labour power and can separate the two. Ownership of capital, of the material factors of production, establishes a relationship between owners and non-owners who only have their labour power. Capital, according to Marx, establishes a social relation of production.

If it is important to observe the expansion of productive capacity for some groups of people, it is equally important to observe the separation of other groups of people from the means of production. Expansion of the means of production is easily observed. Separation of people from the means of production is not sudden, but prolonged, painful and not so easily observed. In agriculture, the critical means of production is land. Separation of labour power from land cannot be treated as a foregone conclusion abstracted from the society being examined. But what can be abstracted from other societies are some of the methods used to observe the extent of the separation. Marx, for instance, catalogues the stages of separation of labour power from land observed in some European societies. Even in the three stages when land is owned by the landlord, the conditions for applying labour power to this land vary from rent-in-kind, to sharecropping, to money rent. The important concept to note is that the separation of labour power from land is indicated by these conditions for applying labour power to land. And these conditions are given by the forms of use of labour power and land, that is labouring conditions and land rental.

Therefore, when capital is redefined as a social relation of production, its development can be observed by a fourth condition:

(iv) The specific social forms of use of factors of production, like labour power and land.

Now it can be seen that when capital is defined as a physical construct, its accumulation has to be defined as the expansion of physical production capacity. This leads to an examination of the physical conditions necessary for such expansion of assets, inputs and profits. But when capital is additionally redefined as establishing a social relationship between the owners of capital and the owners of labour power, its development has to be defined by the social form of use of factors of production. This leads to an examination of the social conditions that accompany physical expansion, of the degree of separation of labour power from land and its variation between regions. Therefore, the physical and social definitions of capital are complementary successive analytical steps, revealing different aspects of the process of accumulation of capital. These steps also lead to more detailed specification of agrarian change.

The Exogenous Endogenous Mechanism

Since these four conditions of accumulation are expected to vary between 
groups of producers and between regions, an exogenous endogenous framework is well suited to explain this variation. Exogenous factors can be defined as those factors that lead to homogeneity in producers' accumulation between regions. Endogenous factors can be defined as those factors that lead to variation in producers' accumulation between regions. This implies that the exogenous factors of agrarian accumulation are (a) not considered to be determined within the agrarian sector and therefore (b) are not specific to any region within the agrarian sector and therefore, (c) have a generally common impact on producers' accumulation between regions. It also implies that the endogenous factors of agrarian accumulation are (a) considered to be determined within the agrarian sector and therefore (b) have to be specific to some region within the agrarian sector and therefore (c) will lead to variation in producers' accumulation between regions.

Therefore, a producers accumulation in a region will be determined by the interaction of a set of exogenous factors with a set of endogenous factors. The exogenous factors will explain homogeneity in producers' accumulation between regions. The endogenous factors will explain variation in producers' accumulation between regions.

Two such exogenous factors are important. State policy is the pre-eminent factors. State policy on pricing, credit and land legislation has a common influence on all regions. Therefore, it introduces homogeneity in producers' accumulation between regions. When state policy discriminates between regions, to develop the public endowments of one region relative to another, these endowments are considered endogenous to the region. This differential in regional endowments leads to a differential in producers' accumulation between regions. It is also important to consider only effective legislation as an exogenous factor. Omitted legislation which leaves the structural characteristics of the agrarian sector as they are, cannot be considered as an exogenous factor. Otherwise all endogenous factors of the agrarian sector become the results of either committed or omitted state policy.

The second exogenous factor is population dynamics. Population growth and the social pattern of inheritance affect the level of assets. They also affect the level of wages through the labour supply. These population dynamics are not expected to vary between regions and so have a common impact on producers' accumulation between regions.

There can be many endogenous factors affecting agrarian accumulation. The primary endogenous factors in the Punjab for instance and its regions are considered to be: the distribution of land-ownership and operation, irrigation endowments, other infrastructure, the form of land rental, the state of factor markets, the topography and the cropping pattern. These factors are endogenous to the agrarian sector, specific to each region and therefore can vary between regions. They can be the product of exogenous factors like regionally discriminating state policy, but they vary between region. And because they vary between regions they lead to variation in producers' accumulation between regions.

\section{THE GENERAL FRAMEWORK FOR ANALYZING AGRARIAN ACCUMULATION: ITS SPECIFICATION}

The physical and social definitions of capital and the sectorally and regionally exogenous and endogenous determinants of their change give a general framework within which agrarian accumulation can be analyzed. Producers' capital accumulation in an agrarian region is determined by factors exogenous to the agrarian sector and the region and factors endogenous to the agrarian sector and the region. This allows regional heterogeneity in the level and pattern of accumulation. Exogenous factors like state policy, and population dynamics have a common influence across the agrarian sector and promote homogeneity in producers' accumulation between regions. Endogenous factors like the distribution of land-ownership and operation, irrigation endowments, the form of land rental, the state of other markets, the topography and the cropping patterns, are specific to regions within the agrarian sector and so promote variation in producers' accumulation across regions.

Private capital accumulation is indicated by physical capacity expansion and is expected to vary across groups of producers. Accumulation is also seen in the changing social forms of use of factors production, like labouring conditions and land rental, to accommodate capacity expansion for some groups and deprivation for others.

The extremely abstract framework developed here can be made specific fo empirical analysis of a particular agrarian sector. Specification consists of filling in specific exogenous and endogenous factors to hypothesize, test and explain observed change in the conditions of capacity expansion and forms of use of labour power and land.

\section{REFERENCES}

Ellis, F. (1988). Peasant Economics. Cambridge: Cambridge University Press. pp. $212-216$.

The entire set of Marxist readings on the Indian mode of production debate make this assumption regional homogeneity in a highly varied subcontinent. See of Vanguard, (eds.) (1978), Studies in the Development of Capitalism in India. Neoclassical assumptions of regional homogeneity abound in studies of Pakistani agriculture. See of M. H. Khan (1979), "Farm Size and Land Productivity". Pakistan Development Review. Vol. XVIII, No. 1.; A. Salam (1981), "Farm Tractorization, Fertilizer Use and Productivity of Mexican Wheat in Pakistan". Pakistan Development Review. Vol. XX, No. 3; S. J. Burki (1976), "The Development of Pakistan's Agriculture". In R. D. Stevens et al.(eds.), Rural 
Development in Bangladesh and Pakistan. Honolulu: University Press of Hawaii.

Hayami, Y. (1981). "Induced Innovation, Green Revolution and Income Distribution". Economic Development and Cultural Change. Vol. 30, No. 1.

Hayami, Y., and M. Kikichi (1981). Asian Village Economy at the Crossroads. Chapters 4-9. Tokyo: University of Tokyo Press.

Hayami, Y., and V. Ruttan (1985). Agricultural Development: An International Perspective. Second Edition, Chapter 4. Baltimore: The Johns Hopkins University.

De Janvry, A. (1973). "A Socioeconomic Model of Induced Innovations for Argentine Agricultural Development”. Quarterly Journal of Economics. R. Grabowski, (1979). "The Implications of an Induced Innovation Model". Economic Development and Cultural Change. Vol. 27, No. 4; F. Ellis, (1988). op. cit. pp. 221-222.

Marx, K. (1973). Capital. Vol. 1. London: Penguin. p. 989.

Marx, K. (1981). Capital. Vol. 3. London: Penguin. p. 763, 955.

Pasinetti, L. (1981). Structural Change and Economic Growth. Chapter 9. Cambridge: Cambridge University Press.

\section{Comments on \\ "A General Theoretical Framework for Analyzing Capital Accumulation in Agriculture"}

Briefly, the paper presents the definitional base for developing a paradigm to examine national capital accumulation by farmers. It does this by first comparing and contrasting general frameworks that are for the most part claimed to be "exogenous" or "endogenous". After the contrast and comparison a framework which is supposed to capture the "best of both" is presented as "An Exogenous Endogenous Framework". The idea is that the exogenous framework would use factors as state policy and population dynamics to explain capital accumulation. The endogenous framework would use factors as land-ownership and operation, irrigation endowments, the form of land rental, the state of other markets, the topography and the cropping patterns to explain capital accumulation. The exogenous endogenous framework would use both sets of factors with the exogenous factors explaining the national level of capital accumulation and the endogenous factors explaining the differences in regional level accumulation. Finally, capital is defined as both a physical and social phenomenon. From a physical perception capital is viewed as production capacity and from a social focus capital is the relationship it establishes between owner of capital and non-owner of capital.

\section{The Objective}

The major problem with the paper is that it does not give guidance to the reader as to its objective. The title suggests that a framework is going to be developed for "analyzing capital accumulation in agriculture". In contrast the text of the paper indicates that, "The objective of this study is to examine accumulation of agricultural capital by producers because it increases output". Since the paper in the end appears to be an attempt at describing a theoretical framework the objective suggested by the title seems more accurate. However, the adherence to a simple theoretical framework makes the paper somewhat trivial without an examination of empirical studies in the same area. In this same context another problem is the definition of capital being considered by the author in the development of the framework. The paper under the heading, "The Notion of Capital" seems to use "scale of output capacity" as a proxy for capital. It also encompasses the Marxian 
concept of social relation to production. In short, the theoretical framework sets the background for a model to explain accumulation of physical capital or a proxy for capital as scale of output capacity but little is developed for paradigms on social capital.

\section{What Is Meant By Exogenous and Endogenous?}

In this paper exogenous factors are generally those thought to "promote homogeneity in producers' accumulation between regions" and endogenous factors to, "promote variation in producers' accumulation across regions". A more common definition is to consider exogenous factors as those that are outside the control of the farmer and endogenous factors as those the farmer controls. After all it is the farmer who accumulates capital. For example, under this definition the irrigation system above the nakka would be exogenous. The irrigation system below the nakka is controlled by the farmer and is endogenous. Other factors as topography, credit conditions, available markets and transport costs would be exogenous.

\section{In Summary}

In brief the paper develops a broad definition of a framework for considering capital accumulation at the farm level. The framework is focused on state policy, population dynamics, land-ownership, irrigation endowments, land rental, the state of markets and cropping patterns as economic phenomenon that explain farm capital accumulation. The paper does not develop a theory as the basis for the explanation nor does it include an examination of empirical studies that confirm or reject elements included in the framework.

Forrest E. Walters

Directorate of Agricultural Policy, Economic Analysis Network Project, Islamabad 